\title{
Oost- en West-Vlamingen uit de 17de eeuw, 'berucht van toverie'
}

W.L. Braekman

Het fenomeen van de heksenvervolging in de Nederlanden en elders in Europa heeft sinds lang de blijvende aandacht gehad van onderzoekers op velerlei gebied. ( ') Van sommige processen die tegen hen, meestal maar niet alleen vrouwen, zijn gevoerd, bezitten we een min of meer volledige schriftelijke neerslag. Dit is bijvoorbeeld het geval voor de beruchte processen die te Laarne in het begin van de zeventiende eeuw zijn gevoerd en enkele jaren geleden weer in de aandacht zijn gekomen. $\left({ }^{2}\right)$ Van andere procesbundels zijn in archieven slechts fragmenten bewaard die niettegenstaande hun onvolledigheid, het toch mogelijk maken zich een beeld te vormen van wat er precies gebeurd is en van de context waarin het proces dient gesitueerd te worden. $\left({ }^{3}\right)$

Een vervolging wegens hekserij kwam dikwijls pas op gang wanneer een baljuw meende gevolg te moeten geven aan geruchten die de ronde deden als zou een bepaalde dorpeling een tovenaar of toverheks zijn. Hij stond aldus bekend, was daarvoor 'berucht' of "befaemt" zoals dat in de documenten heet. Voortgaande op deze geruchten en verdachtmakingen kon de baljuw al dan niet overgaan tot een informeel onderzoek, b.v. een getuigenverhoor, de zgn. "informatie preparatoire". Dit is dan de basis voor het al dan niet beginnen van de eigenlijke gerechtszaak. De baljuw speelde in dit soort zaken dus een heel belangrijke, zeg maar 'vitale', rol en dat in meer dan één betekenis.

(1) Een paar studies zijn: F. Van Hemelrijck, Heksenprocessen in de Nederlanden (Leuven, 1982) en J. Monballyu, Van Hekserij beschuldigd. Heksenprocessen in Vlaanderen tijdens de 16 de en de 17de eeuw (UGA, Kortrijk-Heule, 1996).

(2) J. Monballyu, Idem.

(3) Een voorbeeld is W.L. Braekman, 'Heksen uit Ninove en Pollare in 1595 voor het gerecht', Volkskunde 9l (1990), 1-33.
Naast de goed gedocumenteerde gevallen van hekserij vindt men in archieven en handschriften bij gelegenheid ook allerlei aanwijzingen voor het bestaan van verdachten, mensen over wie gezegd werd dat ze wat met toverij en hekserij hadden. Ook zijn er echo's van processen die zouden gevoerd zijn maar waarvan geen andere substantiële informatie beschikbaar is. Meestal treft men deze heel summiere verwijzingen aan in archievenbundels, die in essentie helemaal niets met het onderwerp te maken hebben. Terloops, als het ware toevallig, wordt er soms gerefereerd aan een heks, een proces, een vonnis of een terechtstelling wegens toverij of wat daarvoor in de ogen van tijdgenoten moest doorgaan. In de regel zijn het berichten, die - hoe frus- 
trerend ook wegens hun onvolledigheid en beknoptheid voor wie er het fijne wil van weten - ons toch een beter inzicht verlenen in de verspreiding van het 'hekserij'-fenomeen. Ook geven ze enig idee van het sociale effect dat deze geruchten - met of zonder erop volgende rechtsvervolging - hadden op de stigmatisering binnen de leefgemeenschap van de terecht, maar dikwijls allicht ook onterecht, als heks of tovenaar aangewezen personen.

In de hiernavolgende bladzijden worden een aantal archiefvondsten samengebracht, die met toverij rechtstreeks of onrechtstreeks verband houden. Ze worden in chronologische volgorde geordend. De vondsten hebben betrekking op dorpen of streken van FransVlaanderen tot het noorden van Oost-Vlaanderen en dateren van 1604 tot het einde van de zeventiende eeuw. De gebruikte bronnen zijn in de eerste plaats verscheidene genadeverzoeken, maar ook andere archieven, zoals het notariaatarchief, het archief van de Raad van Vlaanderen, een kroniek en een verzamelbundel van verhalen en notities aangelegd door een Gentse pater. Deze laatste bron, een vreemde eend in de bijt, bevat een ongewoon gedetailleerd verhaal dat een scherp contrast vormt met wat we in de andere bronnen aantreffen. Vermelden we nog dat de volgende plaatsen ter sprake komen (in alfabetische volgorde): Ardooie, Bavikhove, Belle, Kaprijke, Laarne, Lovendegem, Nazareth, Nevele, Veurne, Watervliet en Westcappel (vroeger Arnoutscappel).

\section{Westcappel : Tovenaar verbrand (1604)}

In 1604 was de schoonvader van Merten Verschaven uit Arnoutscappel (de oude naam voor Westcappel), gelegen aan de IJzer nabij Bergues (Bergen), tot de dood veroordeeld. $\left({ }^{4}\right) \mathrm{Hij}$ zat in de gevangenis, wellicht te Bourbourg opgesloten ("ghevanghen om tooverije") in afwachting van de uitvoering van het vonnis. De naam van de man wordt helaas niet vermeld. Merten, de schoonzoon, had gehoord dat de veroordeelde "des ander daechs zoude gheexecuteert wordden metten viere", d.i. levend zou worden verbrand. Hij was door die informatie geheel van streek, "dinckende wat tsanderdachs zijn kinderen grootvaeder stont te gheschieden". Nadat hij een feest van ondertrouw bijwoonde en daar wellicht wat teveel gedronken had, komt hij samen met een gezel - wellicht op weg naar huis - op "Mueninck-buere", d.i. Monnequebeure, de naam van het gerechtshof te Bourbourg (dépt. du Nord). Daar ontmoeten ze een soldaat, een zekere Carré. Ze meenden dat deze soldaat aanwezig was toen de procureur de schoonvader van Merten "int crimineel proces quaelick gedient" had. Hij had geen eerlijk proces gekregen, zo dachten ze althans. De soldaat wordt aangevallen en doodgestoken. Merten Verschaven dient een genadeverzoek in bij de vorst, maar of het inge-

(4) RA Brussel, Geheime Ruad, Spaanse Tijd, nr. 916. 
willigd werd, weten we niet. Dit geldt trouwens ook voor alle die hierna ter sprake komen.

\section{Bavikhove: mishandeling van een vrouw, verdacht van toverij (1607)}

Pieter de Vlaminck, een "landtsman" of landbouwer, was in deze deelgemeente van Harelbeke, kasselrij van Kortrijk, al jaren geplaagd met tegenslag op zijn boerderij. (5) Hij was, zoals hijzelf het uitdrukt "continuelijcken grootelyckx overvallen ende gequelt", voortdurend en sterk geplaagd met "vrempde plagen die men hem zeijde te wesen tooverije". Zijn vrouw was al jaren lang ziek, zijn dochter was gestorven en dan liep hij gevaar ook nog zijn zoon te verliezen. Al zijn lammeren, koeien en paarden waren doodgegaan. Kortom, het was allemaal doffe ellende. Ze had tot gevolg dat de boer "gevallen was in geheele ruijne", totaal geruïneerd was, "soo hij noch is". Al die tijd had hij "vermoeyen ... op sekere oude vrouwe" die in zijn buurt woonde en was "genaempt Susanna Doornaert". Deze vrouw was immers "vermaert ... voor een tooveresse". Alhoewel hij haar verdacht de hand te hebben gehad in zijn tegenslagen en miserie, "dies nyettemin en heeft [hij] haer noyt eenich semblant gemaeckt van quaede presumptie", haar nooit laten blijken dat hij haar verdacht. En dan gebeurde er iets dat de spreekwoordelijke emmer deed overlopen. Op 2 januari 1607 komt boer De Vlaminck 's avonds thuis en vindt zijn vrouw en de "maerte" al uren bezig met karnen zonder boter te kunnen krijgen. De boer roept vol woede: "Ick zal die hoere haer vleesch in stucken smijten, oft diergelijcke woorden". Het was natuurlijk algemeen bekend dat tovenaressen konden beletten dat bij het karnen boter afgescheiden werd. Toen dit gebeurde, was ook een zekere Jacques Dekuere aanwezig, een vriend van De Vlaminck, die "gewoone was met hem te vogelen naer pertrijsen bij nachte", met hem 's nachts op vogeljacht ging. Deze vroeg aan De Vlaminck of hij meeging "pertriseren", patrijzen vangen. Beiden vertrokken daarop en onderweg vertelde Jacques dat ook hij door de oude vrouw betoverd was. De koewachter van De Vlaminck, Wauterken Pattrijn, een jongen van ca. 14 jaar, voegt zich bij hen en deze laatste wil de oude vrouw dadelijk "gaen smijten", gaan slaan. Wanneer ze op de heerlijkheid "Oeyegem" (?) aan het huis van de alleenwonende Susanna Doornaert komen, heeft Dekuere "een stocxken van eenen tronck gesneden" waarop de drie het huis van de vrouw binnendringen, dan "gesamentlick de voorn[oemde] Susanne gesmeten daer sij te bedde lach". Boer De Vlaminck zelf, "sijnen poignaert uuijtreckende, heeft haer bij den hals genomen, smijtende metten appel vanden selven poignaert soe op den rugge als elders". De vrouw werd zwaar toegetakeld en sterft. Pas vier dagen later vindt men haar dood in haar bed. Vrezende wegens dood-

(5) RA Brussel, Geheime Raad, Spaanse Periode, nr. 918. slag of moord vervolgd te worden, dient De Vlaminck een genadeverzoek in. 


\section{Lovendegem: vrouw verdacht van toverij (1607)}

In juni 1607 werd door de Gentse notaris Jan Jacobssen een "informatie preparatoire" gehouden, een getuigenverhoor, in verband met een zekere Catherine Wille, de echtgenote van Pieter Callant. $\left(^{6}\right)$ Deze "informatie" werd gehouden op verzoek van deze laatste die niet ver van Gent, te Lovendegem de hofstede "t hof ten broucke" uitbaatte. Catherine Wille had de naam "eene tooveresse" te zijn en als voorzorgsmaatregel tegen een mogelijke aanhouding en inbeschuldigingstelling door de baljuw, laat Pieter, haar echtgenoot, allerlei getuigen voor de notaris verklaren dat daar niets van aan is. Dit was een voorzorgsmaatregel, een "actie van injurie", tegen eventuele gerechtelijke vervolging, $\left({ }^{7}\right)$ een "purgie" tegen verdere aantijgingen. $\left.{ }^{8}\right)$ Als men wist dat men de reputatie had een heks te zijn en hiertegen niets ondernam, was dit volgens de demonologen op zichzelf al een belangrijke aanwijzing van schuld. $\left({ }^{9}\right)$ Zo is er Jonkvrouw Jacquelijne vanden Bossche, de weduwe van Pieter Marten Snouckaert, heer van Zomergem. Ze komt verklaren "noynt ghehoirt oft ghesien thebbene eenighe zaecken ofte suspitien daer uute [ze] soude bemerct hebben dat de selve Catherine zoude wesen eene tooveresse, zoo eenighe persoonen haer willen naer segghen", over haar het gerucht verspreiden. Integendeel, zegt ze, namelijk "dat sij haer altijts ghedreghen heeft Godtsvruchtich, eerlick ende rechtveerdelick in alle haer conversatie ende handele". Dat is een klare en duidelijke getuigenis van iemand die in de rurale gemeenschap een positie van aanzien bekleedde. Onder de vele andere getuigen die allen in dezelfde zin spreken, laten we nog even een oud-schepen van Lovendegem aan het woord, een zekere Geerolf Claijs. Die verklaart eveneens dat hij niet weet dat vrouw Wille een "toveres" zou zijn, maar ongevraagd en domweg voegt hij daaraan toe "dat hij van haer sulcx wel heeft hooren segghe". Het gerucht deed dus blijkbaar wel degelijk de ronde ...

\section{Ardooie: vermeende tovenares (1608)}

Te Ardooie in het Mosserambacht (kasselrij van Ieper) leeft op de wijk "Crupindeerde", Kruip-in-d'Aarde, Jan Hanecourt met vrouw en kinderen. $\left({ }^{10}\right)$ Zijn echtgenote was al lang "sieckerterich", ziekelijk. Op het dorp deed het gerucht de ronde, het was zelfs de "gemeene opinie", dat deze ziekte het gevolg was van toverij. Te meer daar op het dorp Margriete woonde, de vrouw van Cornelis Bollaert, "befaemt ende berucht" voor toverij. Het was dus logisch te denken dat zij verantwoordelijk was voor de ziekte van Hanecourts vrouw. Deze laatste probeert Margriete met dreigementen ertoe over te halen de ziekte van zijn vrouw te doen ophouden. Wie kan toveren kan immers ook onttoveren. Hij bedreigt de vrouw met zijn roer, een soort geweer, dat “loopt af", lost een schot, geheel toevallig en per ongeluk, zegt hij, maar in alle geval met als resultaat dat Margriete dood is. Op 27 juni

(6) RA Gent, Oud Notariaat, nr. 702.

(7) Het rechterlijk archief van de baronie Lovendegem is voor de vroege zeventiende eeuw niet bewaard.

(8) Cf. J. Monballyu, Op.cit., p. 30 31.

(9) Idem, p. 27.

(10) RA Brussel, Geheime Ruad, Spaanse periode, nr. 926. 
1608, de dag na de feiten, wordt een "informatie", een getuigenverhoor gehouden door de baljuw met het oog op een eventueel proces wegens moord. Jan Hanecourt vreest het ergste en dient prompt voor alle zekerheid een genadeverzoek in.

\section{Watervliet: vermeende 'toveres' neergeschoten (1608)}

Joosijne Boelins, de echtgenote van Gernoult Verbeke, was te Watervliet aan de Leopoldvaart in het Meetjesland "seer befaemt ende gehouden ... vande meestendeel vande inwoonders voer een tooveres$s e^{\prime \prime}$ (")

Een zekere Matthijs Corthal, die in deze gemeente een landbouwbedrijf uitbaatte, had in zijn gezin en op zijn hoeve sinds jaren te kampen met allerlei tegenslag en ellende. Hij had "geleden ... groote schade ende verdriet". Hij had al zijn koeien en zwijnen verloren, daarna was zijn kind "seer miserabel geworden ende heeft moeten geholpen wordden bij eenen geestelijcken persoon". Wellicht heeft deze geestelijke het kind belezen. En of dit nog niet genoeg was, is "doen tselve quaet oijck gevallen op zijne huysvrouwe". Het gevolg van dit alles was dat de boer "verloren ende in aermoede verteert heeft alle zijn middelen, waerdeure hij raeloos was gelijck een desperaet mensche", een wanhopig iemand. De dorpsgenoten verzekerden hem "dat dyes geschiede door tdoene vande voerseide Joosijne", wat Corthals trouwens ook zelf geloofde. Toen hij aldus volop leed, gebeurde het dat de boer op een bepaald ogenblik zei tot Joosijne: "Maer, Joosijne, hoe condt ghij mij dit doen, en hebdij mij nijet quellinge ende verdriet genouch gedaen?". Daarop antwoordde Joosijne: "Hoe ik, Matthijs, ende houdt ghijt op mij?", wat we ongeveer als volgt kunnen 'hertalen': wat zou ik, en verdenk je mij? Een antwoord vol ongeloof. Maar daar bleef het niet bij. Deze conversatie had plaats bij de ingang van het hof van Corthals. Deze is helemaal niet tevreden met het antwoord van Joosijne. Hij loopt in huis en keert terug met zijn roer waarmee hij de vrouw in de buik schiet. Ze overlijdt en Matthijs vraagt de koning om genade.

\section{Laarne: vrouw verdacht van toverij (1609)}

Een zekere Jan de Coene was op zondag 27 september met zijn vader Michiel in de herberg van Bartholomeus van de Kerckhove te Laarne, ten oosten van Gent. Bij de gesprekken die onder de klanten werden gevoerd, kwam op een bepaald ogenblik de dochter van Maarten de Vos ter sprake. Jan de Coene had die lief en wilde met haar trouwen. Zijn vader probeerde hem dat uit zijn hoofd te praten door hem ervan te overtuigen dat dit meisje geen geschikte partij voor hem was, "ten opsiene dat men van de moedere van de voor seide dochter was zegghende dat sij befaemt was van tooverije". ('2) Er ontstaat een

(11) RA Brussel, Geheime Raad, Spaanse periode, nr. 923.

(12) RA Brussel, Geheime Raad, Spaanse periode, $\mathrm{nr} .930$. 
gevecht waarbij De Coene junior iemand doodsteekt. Een ongeluk, zonder opzet, beweert hij in een genadeverzoek aan de koning. Tot daar dit heel kort bericht. $\mathrm{Nu}$ is het een welbekend geloof dat een moeder die toverheks is haar dochter in de zwarte kunsten opleidde en haar kennis aan haar doorgaf. In de beruchte heksenprocessen die te Laarne in 1607-1608 plaatsvonden, komt de familie De Vos inderdaad ook ter sprake. $\left({ }^{13}\right)$ Op het einde van augustus 1607 diende baljuw Jan Schepens aldaar een aanklacht in tegen een zekere Paesschijne Neijts. Nog dezelfde maand werd ze gefolterd waarop ze al vlug tot volledige bekentenissen werd gebracht. Ze verklaarde dat ze samen met een tiental anderen op twee heksenbijeenkomsten aanwezig was geweest. Gevraagd de namen van de anderen bekend te maken, zegt ze dat een van hen Catharijne was, de echtgenote van Maarten de Vos, die, zo voegt ze er nog aan toe, "getekend was omtrent haer linkerborst en vergezeld van haer boel (minnaar) die Paesschier heette". $\left({ }^{14}\right)$

\section{Nazareth: tovenares verbrand? (1610)}

Het volgende wel heel bondig en daardoor heel frustrerend bericht is een passage uit een ruzie. In hoeverre het ernstig te nemen is, valt evenmin met zekerheid te zeggen. Hans van Hecke en Jan de Bels zijn samen op weg naar Leerne, d.i. St.-Martens-Leerne, het Leiedorp. Ze krijgen ruzie en De Bels verwijt Van Hecke "te wesen eenen jonghen dief ende tooveraire". En, zo voegt hij daar nog aan toe "sijn eijghen moeye (tante) in de prochie van Nazarette om tooverie an eenen staeck ghebrandt was". $\left({ }^{15}\right)$ Of dat met de waarheid overeenstemt, is onzeker. In alle geval, van een heksenverbranding te Nazareth heb ik nergens een spoor gevonden, wat niet noodzakelijk betekent dat die er niet geweest kan zijn.

\section{Nevele: tovenares doodgefolterd (1624)}

Pieryne Daniels, echtgenote van Loys Winckelhaeck, werd door de schepenbank van Nevele beschuldigd van toverij. $\left({ }^{16}\right)$ Daaraan moet een door de baljuw georganiseerd getuigenverhoor voorafgegaan zijn, maar daarvan is geen spoor meer te bekennen. Het gevolg is alvast dat we niet kunnen achterhalen hoe de beschuldigingen precies luidden. De schepenen hadden advies gevraagd en gekregen - zo beweren ze althans - van de Raad van Vlaanderen te Gent, waartoe ze wettelijk verplicht waren om misbruiken te voorkomen. Handelend naar dit advies zijn ze overgegaan tot foltering om de beschuldigde aldus tot bekentenissen te brengen. De vrouw sterft tijdens de foltering en de baljuw George Dhondt, burgemeester Josse de Meyere en schepen Jean van Speybrouck, dienen zich voor het gerecht te verantwoorden. Ze worden ervan beschuldigd helemaal niet aan vijf of minstens drie neutrale advocaten van de Raad van Vlaanderen advies gevraagd te hebben, dit in tegenspraak met wat ze zelf beweren. Verder blijkt dat
(13) J. Monballyu, 'Heksenprocessen te Laarne in 1607-1608: een samenspel van 'krachten van onderen' en 'krachten van boven'. In: Gedenkschriften Oudheidk. Kring Land van Dendermonde (2002), pp.191-244.

(14) Idem, p. 202.

(15) RA Brussel, Geheime Rraad. Spaanse periode, $\mathrm{nr} .925$.

(16) RA Brussel, Geheime Raad, Spaanse periode, nr. 955. 
er geen advocaat van dit hoogste gerechtshof bij de foltering aanwezig was. Dit heeft het mogelijk gemaakt dat Pieryne "soo extraordinairlick, vreedelick, onredelick ende onmenschelick gehandelt ende ghetracteert is gheweest". Pieryne werd twee nachten lang gefolterd door haar het slapen te beletten, zittend op een stoel vóór het vuur en aan de wanden van de kamer aan de handen vastgemaakt en met een halsband om, van binnen voorzien van pinnen. Geleidelijk werd ze steeds dichter bij het vuur geplaatst. Daardoor en natuurlijk ook door de toenemende slaapneiging ging ze minder strak rechtop zitten zodat de pinnen van de halsband dreigden haar te kwetsen. $\left({ }^{17}\right)$ Bovendien werd ze ondertussen met scherpe roeden op haar bloot lichaam gegeseld, "soo van vooren op de boesemen, aermen ende andere haere leden, als van achtere". De beul heeft tenminste vier "bessemen" of bezems op haar lichaam in de loop van de nacht stukgeslagen. Pieryne werd ook verplicht te zitten op het scherp van een driepikkel, "de voeten ende beenen (los) vande aerden, gebonden en gherect". Maar wat de beul nog het meest op de heupen werkte, was dat Pieryne gedurende haar hele foltering luid zong, zo luid dat men haar in de hele gevangenis kon horen. Toen de aanwezige schepenen bij de beul of scherprechter geprotesteerd hadden, had die hen afgesnauwd, "qu'on le laisseroit faire puisqu'il scavoit son métier". Daarop hadden de schepenen gezwegen en hadden verder niet meer durven tussenkomen. Ze lieten de scherprechter dan maar zijn beroep uitoefenen, wat in dit geval uiteindelijk het gevolg had dat Pieryne Daniels er het leven bij inschoot.

Het wordt niet expliciet gezegd, maar het is duidelijk dat de schepenen van Nevele de schuld voor het gebeuren in de schoenen van de beul wilden schuiven. Opvallend daarbij is dat deze zelf niet met naam en toenaam wordt vermeld. Was het de toenmalige beul van Gent, $\left({ }^{18}\right)$ Abraham Balthazar, die ze hadden ontboden? Verder vernemen we wel dat hun vertrouwen in de anonieme beul was toegenomen toen die het lichaam van de vrouw had 'gevisiteerd' of onder-

(17) Ook Pieter Geldof uit Noordschote werd in 1660 met de halsband gefolterd: cf. W.L. Braekman, Spel en Kwel in vroeger Tijd (Gent, 1999), pp. 131-152 en ook Catharina Cursse onderging in 1598-1599 te Assenede hetzelfde lot: cf. dezelfde, "Twee heksen te Assenede (eind 16de en midden 17de eeuw)", In: Appeltjes van het Meetjesland 49 (1998), pp. 57-71. (18) P. Claeys, Le Bourreau de Gand (Gand, 1893), p. 35 en passim.

(19) Cf. J. Monballyu, Op.cit., p. 59. zocht en daarbij niet één maar twee zgn. duivelstekens had ontdekt. Een algemeen aanvaard bewijs was dit dat men wel degelijk met een tovenares of heks te doen had. Onder demonologen werd algemeen aangenomen dat de duivel tijdens het paren met een heks een stigma of teken op haar lichaam aanbracht. $\left({ }^{19}\right)$

Ook dit feit moet verklaren waarom de schepenen van Nevele de beul de vrije hand hadden gelaten. Toch zijn ze er niet helemaal gerust in en vrezen ze voor het gebeurde vervolgd te worden. Voor alle zekerheid richten ze zich alvast tot de koning met een genadeverzoek, waaruit de bovenstaande gegevens allemaal afkomstig zijn. Daarin argumenteren de schepenen dat ze maar eenvoudige lieden van te lande zijn. Geheel te goeder trouw hebben ze zich laten leiden door 
wat specialisten in dergelijke materie hun hadden aangeraden en wat een andere specialist, de beul, een man die beroepshalve met dergelijke zaken vertrouwd was, nodig had gevonden te doen om de beschuldigde tot bekentenissen te dwingen.

\section{Belle (Bailleul): berechtiging van 'toveresse' (1657-1660)}

In deze buitengewoon interessante, maar weinig bekende kroniek, lezen we het volgende, bijzonder beknopt bericht. $\left({ }^{20}\right)$ Het luidt: "In dit jaer (1658) en het jaer te vooren heeft men te Belle begonnen toveressen ophalen en te geregtigen. Dit gedeurde (= duurde) tot het jaer 1660". "Ick en wil hier van niet particulierlyck (= in detail) spreken om redenswille", voegt de anonieme auteur uit de tweede helft van de zeventiende eeuw er nog aan toe. Men kan alleen vermoeden dat de Duinkerkse beul Jan Noorman hierbij betrokken was. Achtergrond en andere gegevens ontbreken helaas volledig.

\section{Kaprijke: een echtpaar vervolgd? (1678)}

Op 19 december 1678 wordt voor de Raad van Vlaanderen ondervraagd zekere Jan Huyghe, 27 jaar oud, gezworen landmeter van de stad en de vrijheid van Kaprijke in het noorden van het Meetjesland. ${ }^{(21)} \mathrm{Hij}$ ontkent dat hij gedreigd heeft zijn broer, de 22-jarige Maximiliaan, baljuw van Kaprijke, zijn roer "tusschen hals ende necke" te leggen, "ter causen hij, balliu, van hunne ouders toveraer ende tooveresse ghemaect hadde". Wat dit laatste precies betekent, is niet duidelijk. Had hij in zijn functie van baljuw zijn ouders voor het gerecht gedaagd op beschuldiging van toverij? Of had hij alleen maar het gerucht verspreid dat ze zich met toverij bezighielden? Jammer genoeg is echter ook over deze zaak geen verdere informatie beschikbaar. Ze moet in alle geval ernstig genoeg geweest zijn om bij het hoogste gerechtshof van Vlaanderen aanhangig gemaakt te zijn.

\section{Veurne: tovenares en dochter geëxecuteerd (late 17de eeuw)}

In scherp contrast met de beknoptheid van het vorige bericht is de gedetailleerdheid van het navolgende merkwaardige verhaal. Het komt voor in een vroeg achttiende-eeuws handschrift, getiteld Verdrijf der Droefheyt en is wellicht samengesteld door J.B. Dobercourt, een Gentse pater augustijn. $\left({ }^{22}\right)$ Jammer genoeg worden daarbij geen namen van personen genoemd en is de datering alleen bij benadering mogelijk. Daar de hand wijst op de eerste helft van de achttiende eeuw en de gebeurtenissen te Veurne zouden voorgevallen zijn toen de vader van de anonieme woordvoerder nog een tiener was, lijkt een datering in de late zeventiende eeuw verantwoord. In hoeverre het bericht berust op historische feiten is moeilijk uit te maken,
(20) L. Debaecker, Kronyke der byzonderste Gebeurtenissen te Belle en omstreken voorgevallen in de jaren 1647-1673 (Rousbrugge, Haringhe, 1860), p. 18.

(21) RA Gent, Raad van Vlaanderen, $\mathrm{nr} .8571$.

(22) U Gent, hs. 1816, p. 51. 
maar niets wijst er met zekerheid op dat dit niet het geval zou zijn. Ziehier het verhaal, zoals het in het handschrift voorkomt: ... Wanneer mynen vader in grammatica $\left({ }^{23}\right)$ in die schole was, hoorde hij van zijnen pater perfect (lees prefect) ${ }^{24}$ ) segghen datter in de stadt van Veurne daarontrent gheschiet was op een prochie van eenen boer die met syn dochterken van ses jaeren oudt ginck in den somer besien sijne vruchten die door de sonne ende het eedt (=heet) weder gheheel uijtdrooghden, doordien dat het in langhen tijt niet ghereghent en hadde, hem seer beclaeghende, crijtende (=schreiende) ende seer bedroeft sijnde.

Het dochterken vraeghde waerom dat hij creedt ende soo bedroeft was. Ende tselve verstaen hebbende van sijnen vader, seijde: 'vaerken, wil ick het doen reghenen?' Ende dat gheseijt hebbende, maeckte het meysken met eenen stock een cleijn putteken, daer in water gietend, ende eenighe woorden ende cruijcen daerover maeckende, begonst terstont de locht te overtrecken met wolcken, donderende ende blixemende, ende begonst soo sterck te reghenen al of hemel ende aerde verginck. Den vader dat kint vraeghende waer dat het dit geleert hadde, seijde (ze): 'wel vaerken, weet ghij dat niet? Moerken heeft het mij geleert!'. Den boer dit ghehoort hebbende, ginck met sijn dochterken naer Veurne bij de magistraet, segghende dat sij sijn kint souden examineren, aen hun tselve verteelt (sic) hebbende, dat sij(n) dochterken gedaen hadde, wiert de moeder ghevanghen ende daer naer verbrant, die daer noch veel andere accuseerde, ende het dochterken wiert tusschen twee bedden $\left({ }^{25}\right)$ versmacht.

Het is algemeen bekend dat heksen kunnen doen regenen, maar in Vlaamse heksenprocessen komt dit exploot zogoed als niet voor. Moeders werden verondersteld - we zagen het reeds hierboven - hun bijzondere macht door te geven aan hun dochter. Beide gegevens zijn dus goed verankerd in de hekserijgeschiedenis, maar het gebrek aan precieze datering en de anonimiteit van de personen kunnen enige twijfel over de authenticiteit verantwoorden. We zullen het wel nooit met zekerheid achterhalen, tenzij - wat onwaarschijnlijk lijkt - alsnog

nieuwe gegevens in dit verband zoude worden ontdekt.

(23) De grammatica-klas was het voorlaatste jaar van de oude humaniora.

(24) Het was duidelijk een jezuïetencollege.

(25) Hoe men zich dit voorstellen moet, is onduidelijk. Wellicht is bedoeld tussen twee beddenkussens. 